\title{
Early diagnosis of serum SICAM-1 and SRAGE in severe acute pancreatitis, and efficacy and prognosis prediction of glutamine combined with ulinastatin
}

\author{
LINI SHAN $^{1}$, SHIXIAN BAI ${ }^{2}$ and MIN ZHAO ${ }^{1}$ \\ ${ }^{1}$ Department of Pharmacy, and ${ }^{2}$ Intensive Care Unit, Yidu Central Hospital of Weifang, \\ Qingzhou, Shandong 262500, P.R. China
}

Received January 20, 2020; Accepted December 31, 2020

DOI: $10.3892 /$ etm.2021.9755

\begin{abstract}
Acute pancreatitis (AP) is a common gastrointestinal disease that can become severe, so that intensive care may be required. This study was to examine serum soluble intercellular adhesion molecule-1 (sICAM-1), and soluble receptor for advanced glycation end products (sRAGE) for efficacy and prognosis prediction of glutamine (Glu) combined with ulinastatin (UTI) on severe acute pancreatitis (SAP). Fifty-four mild acute pancreatitis (MAP) patients admitted to Yidu Central Hospital of Weifang were selected as the MAP group (MAPG), 80 with SAP were divided as the SAP group (SAPG), and 60 healthy individuals who came to Yidu Central Hospital of Weifang for physical examination during the same period were included to the normal group (NG). Serum sICAM-1 and sRAGE were measured and their predictive value of efficacy and prognosis were analyzed. In view of the treatment effectiveness and prognosis, the patients were divided into effective group (EG) and ineffective group (IG), good prognosis group (GPG) and poor prognosis group (PPG). The levels of D-lactate, diamine oxidase (DAO), endotoxin and T-lymphocyte subsets $\left(\mathrm{CD}^{+}\right.$, $\mathrm{CD}^{+}, \mathrm{CD}^{+}$and $\left.\mathrm{CD}^{+} / \mathrm{CD}^{+}\right)$were measured and the changes before and after treatment were analyzed. The AUC values of NG and MAPG, NG and SAPG, MAPG and SAPG were $0.857,0.939$ and 0.856 , respectively, those of predicting efficacy were 0.920 and 0.874 , respectively, and those of poor prognosis in the SAPG were 0.914 and 0.879 , respectively. In the SAPG, D-lactate, DAO, endotoxin and $\mathrm{CD}^{+}$decreased markedly after treatment, but $\mathrm{CD}^{+}, \mathrm{CD}^{+}$, and $\mathrm{CD}^{+} / \mathrm{CD}^{+}$ were opposite. SICAM-1 and sRAGE were also independent risk factors for poor prognosis in the SAPG. Serum sICAM-1
\end{abstract}

Correspondence to: Dr Min Zhao, Department of Pharmacy, Yidu Central Hospital of Weifang, 4138 Linglongshan South Road, Qingzhou, Shandong 262500, P.R. China

E-mail: sln7007@163.com

Key words: sICAM-1, sRAGE, glutamine, ulinastatin, severe acute pancreatitis and sRAGE have high predictive value for early diagnosis, efficacy and prognosis of Glu combined with UTI.

\section{Introduction}

Acute pancreatitis (AP) is the third most familiar gastrointestinal disease with a rising morbidity, with 275,000 cases admitted in the States $(1,2)$. The clinical manifestations are mild, self-limited local inflammation, or severe systemic inflammatory reaction. Severe AP (SAP) patients may require intensive care (3). Additionally, 15-25\% AP patients are likely to progress to SAP, which is manifested as pancreatic necrosis that can lead to various complications, and its mortality is as high as $10-20 \%$ (4). Early intervention for SAP patients is helpful to improve their survival. However, the assessment system of AP severity and imaging diagnosis requires at least $48 \mathrm{~h}$ to ensure accuracy. Furthermore, the detection of laboratory indicators cannot effectively cope with the clinical heterogeneity of SAP patients (5). Therefore, exploring new markers for the early diagnosis of SAP is crucial. At present, the treatment methods for AP include liquid therapy, nutrition therapy, antibiotic therapy and surgical intervention (6). The determination of a clinical treatment plan is generally based on the etiology of patients and possible complications to control the disease (6). The pathological mechanism of AP involves a series of comprehensive processes such as immune system mediation, and complex cascade reaction of inflammatory activation (7). Based on the clinical characteristics and pathological mechanism of AP patients, examination of the therapeutic targets, as well as relevant diagnostic, therapeutic and prognostic evaluation markers is imperative.

Glutamine $(\mathrm{Glu})$ is a functional essential amino acid that can regulate key biological functions, and it is helpful in regulating intestinal mucosal barrier function and relieving immunosuppression $(8,9)$. A study of Glu in acute necrotizing pancreatitis (ANP) rats by Alhan et al explained that using Glu alone significantly reduced the abnormal pathological indexes of rats, suggesting that it could treat AP (10). As an immune nutrient, Glu can be used for nutritional intervention during AP attacks to relieve the inflammatory state of the disease. Its intravenous infusion reduces infection complications and the mortality of SAP patients $(11,12)$. Ulinastatin (UTI) is a trypsin inhibitor obtained by separation and purification of 
human urine, which can stimulate intestinal mucosal dysfunction and immune function recovery in SAP patients $(13,14)$. Previous findings have shown that UTI also reduces the level of inflammatory cytokines and inhibits oxidative stress, which can balance the permeability of vascular endothelial cells through the RhoA/ROCK signaling pathway to start an anti-inflammatory mechanism $(15,16)$. Soluble intercellular adhesion molecule-1 (sICAM-1) is a member of the immunoglobulin superfamily. Its high expression abnormality is related to human diseases such as gastric cancer and pancreatic cancer, and it has certain predictive value for pancreatic necrosis and death in AP patients $(17,18)$. Soluble receptor for advanced glycosylation end products (sRAGE) is a soluble splice variant of the full-length receptor RAGE. It participates in the pathological mechanism of acute inflammation, and can be used as an effective marker for early identification of SAP patients $(19,20)$.

SICAM-1 and sRAGE are soluble molecules involved in pancreatic-related diseases, but there are few studies on the diagnosis, efficacy and prognosis evaluation of AP patients. This study was to determine the diagnostic, therapeutic and prognostic value of the two on AP with Glu and UTI by detecting their serum expression.

\section{Materials and methods}

General data. Totally 134 AP patients treated in the Department of Gastroenterology of the Yidu Central Hospital of Weifang from March 2017 to June 2019 were selected as AP group (APG), comprising 74 male and 60 female patients. All of them were treated with Glu combined with UTI. Inclusion criteria: AP was diagnosed according to the diagnostic criteria of clinical practice guidelines, and further classified as mild acute pancreatitis (MAP) and SAP (21); Acute Physiology and Chronic Health Evaluation (APACHE) II Score (22) was not less than 8; patients were informed and willing to cooperate with this research; patients had no history of allergy to this therapeutic drug. Exclusion criteria: Patients had malignancy, infectious or allergic diseases; patients had taken drugs that influenced the relevant indicators for 6 months; patients had communication or cognitive disorders; patients died within 7 days after admission.

The 134 patients were subdivided into the MAP and SAP groups, each group comprising 34 and 40 male, and 20 and 40 female patients, respectively. Another 60 healthy individuals who came to the Yidu Central Hospital of Weifang for physical examination during the same period were selected as the normal group (NG), comprising 35 males and 25 females. They were $(45.76 \pm 5.84)$ years old on average. We then divided AP patients into the effective (EG) and ineffective (IG) groups in light of the different therapeutic effect of patients; 103 were effective and 31 were ineffective. Based on whether SAP patients died within 30 days, 65 survivals were included in the good prognosis group (GPG) and the dead (15 individuals) in the poor prognosis group (PPG).

All the subjects and their families agreed to participate in the study and signed the written informed consent form. The study was approved by the Hospital Ethics Committee of Yidu Central Hospital (Weifang, China).

Treatment methods. Patients in the APG were treated with Glu combined with UTI. Glu (KS-01055, Shanghai Keshun
Biotechnology Co., Ltd.) (0.4 g/kg) was injected intravenously once a day, while UTI (Shanghai Yubo Biotechnology Co., Ltd.; cat. no. CP-140785) of 105 units was dissolved in 0.5 liter glucose injection for intravenous drip once a day for two weeks. Edaravone combined with UTI was used to treat any patients who did not respond to the Glu combined with UTI treatment.

Assessment of efficacy. Effectiveness was assessed as indicated below: Markedly effective: After treatment, the clinical symptoms of patients were improved significantly; CT examination showed that morphology of abdominal pancreas was normal, blood/urine amylase and white blood cell count and other laboratory indicators returned to normal; effective: After treatment, the clinical symptoms of patients were relieved; CT examination showed that the abdominal pancreatic edema was relieved, and the laboratory indexes such as blood/urine amylase and white blood cell count were improved; ineffective: There was no marked improvement in clinical symptoms after treatment; CT examination showed no obvious improvement in abdominal pancreatic edema, and no marked decrease in laboratory indicators such as blood/urine amylase and white blood cell count. The total effective rate was the percentage of patients with marked effective and effective efficacy in the total number.

Index detection. Altogether $5 \mathrm{ml}$ venous blood was collected from patients in the APG on an empty stomach in the morning of the next day after admission (for efficacy evaluation) and 7 days after treatment (for prognosis evaluation), centrifuged $10 \mathrm{~min}$ at $1,500 \mathrm{x} \mathrm{g}$ at $4^{\circ} \mathrm{C}$ and the serum and plasma were separated and placed in a refrigerator at $-70^{\circ} \mathrm{C}$ for standby. Serum sICAM-1 and sRAGE levels were determined by enzyme-linked immunosorbent assay (ELISA) (23), and this step strictly adhered to the protocol of the human sICAM-1 and sRAGE ELISA kits (China Shanghai Guandao Bioengineering Co., Ltd., GD-E001264474, GD-E001271747). Serum D-lactic acid and diamine oxidase (DAO) levels were determined by spectrophotometry (D-lactic acid, DAO spectrophotometric kits were purchased from Shanghai Yaji Biotechnology Co., Ltd., YS-1132K, YS-1358K), and plasma endotoxin levels were tested via tachypleus amebocyte lysate (endotoxin limulus test kits were provided by Shanghai Xinfan Biotechnology Co., Ltd., XFNDS001). The peripheral blood T-lymphocyte subsets $\left(\mathrm{CD}^{+}, \mathrm{CD}^{+}, \mathrm{CD}^{+}\right.$and $\left.\mathrm{CD} 4^{+} / \mathrm{CD}^{+}\right)$ were measured via flow cytometry (China Changzhou Beamdiag Biotechnology Co., Ltd.; cat. no. 1026).

Statistical analysis. The experimental data were statistically analyzed via SPSS20.0 [Bioeasy (Beijing) Technology Co., Ltd.], and the pictures were drawn via GraphPad Prism 6. The counting data were expressed by number of cases/percentage [n (\%)] and the comparison between two groups was analyzed via Chi-square test. The measurement data were represented as mean \pm standard deviation and compared via unpaired t-test. The comparison before and after treatment was assessed via paired t-test, and univariate analysis was employed for comparison between multiple groups. The risk factors for poor prognosis in SAP patients were analyzed via Logistic regression analysis. $\mathrm{P}<0.05$ denotes there are statistical differences. 
Table I. Comparison of general data $[\mathrm{n}(\%)$, mean $\pm \mathrm{SD}]$.

\begin{tabular}{|c|c|c|c|c|c|c|c|}
\hline Factors & $\begin{array}{l}\text { Normal group } \\
\quad(\mathrm{n}=60)\end{array}$ & $\begin{array}{l}\text { MAP group } \\
\quad(\mathrm{n}=54)\end{array}$ & $\begin{array}{l}\text { SAP group } \\
\quad(\mathrm{n}=80)\end{array}$ & $\chi^{2}$ & F & $\mathrm{t}$ & P-value \\
\hline Sex & & & & 1.878 & & & 0.296 \\
\hline Male & $35(58.33)$ & $34(55.22)$ & $40(50.00)$ & & & & \\
\hline Female & $25(41.67)$ & $20(44.78)$ & $40(50.00)$ & & & & \\
\hline Age (years) & & & & 3.089 & & & 0.187 \\
\hline$<50$ & $26(43.33)$ & $25(52.24)$ & $45(56.25)$ & & & & \\
\hline$\geq 50$ & $34(56.67)$ & $29(47.76)$ & $35(43.75)$ & & & & \\
\hline Average age & $44.55 \pm 5.37$ & $44.98 \pm 4.15$ & $46.16 \pm 4.62$ & & 2.181 & & 0.116 \\
\hline BMI $\left(\mathrm{kg} / \mathrm{m}^{2}\right)$ & $21.87 \pm 2.55$ & $21.78 \pm 2.10$ & $22.45 \pm 1.98$ & & 1.901 & & 0.152 \\
\hline Systolic blood pressure (mmHg) & $125.09 \pm 10.13$ & $127.88 \pm 8.26$ & $126.84 \pm 9.73$ & & 1.280 & & 0.280 \\
\hline Diastolic blood pressure $(\mathrm{mmHg})$ & $79.62 \pm 7.10$ & $82.03 \pm 8.20$ & $81.56 \pm 7.16$ & & 1.759 & & 0.175 \\
\hline History of drinking & & & & 1.878 & & & 0.296 \\
\hline No & $35(58.33)$ & $27(44.78)$ & $33(41.25)$ & & & & \\
\hline Yes & $25(41.67)$ & $27(55.22)$ & $47(58.75)$ & & & & \\
\hline History of smoking & & & & 3.390 & & & 0.170 \\
\hline No & $36(60.00)$ & $26(47.76)$ & $38(47.50)$ & & & & \\
\hline Yes & $24(40.00)$ & $28(52.24)$ & $42(52.50)$ & & & & \\
\hline Place of residence & & & & 1.103 & & & 0.437 \\
\hline Countryside & $21(35.00)$ & $24(43.28)$ & $34(42.50)$ & & & & \\
\hline Cities and towns & $39(65.00)$ & $30(56.72)$ & $46(57.50)$ & & & & \\
\hline APACHE II scores & - & $10.87 \pm 2.38$ & $20.36 \pm 4.13$ & & & 15.251 & $<0.001$ \\
\hline
\end{tabular}

MAP, mild acute pancreatitis; SAP, severe acute pancreatitis; BMI, body mass index.

\section{Results}

General data. There was no statistical difference in sex, age, average age, body mass index (BMI), systolic blood pressure, diastolic blood pressure, history of drinking or smoking, place of residence and other aspects between the three groups $(\mathrm{P}>0.05)$. Thereinto, the average APACHE II scores of the MAP group (MAPG) and the SAP group (SAPG) were $(10.87 \pm 2.38)$ and $(20.36 \pm 4.13)$, respectively (Table I).

Expression of serum sICAM-1 and sRAGE. The serum sICAM-1 and sRAGE levels in the SAPG were markedly higher than those in the MAPG and the NG, and the levels in the MAPG were markedly higher than those in the NG, with statistically marked differences $(\mathrm{P}<0.05)$. Before treatment, the two levels in the the SAPG were markedly higher than those in the MAPG. After treatment, the levels in the SAPG were dramatically lower than those before treatment, but still higher than those in the MAPG, with statistically marked differences $(\mathrm{P}<0.05)$ (Fig. 1).

Diagnostic value of serum SICAM-1 and sRAGE. After conducting ROC curve analysis, we found that the AUC value of serum sICAM-1 in diagnosing NG and MAPG was 0.799, and the best cut-off value was $1.12 \mu \mathrm{g} / \mathrm{ml}$; the AUC value of serum sRAGE in diagnosing NG and MAPG was 0.786, and the best cut-off value was $393.10 \mathrm{pg} / \mathrm{ml}$; the AUC value of serum sICAM-1 combined with sRAGE in diagnosing NG and MAPG was 0.857 , and the best cut-off value was 0.61 ; AUC value of serum sICAM-1 in diagnosing NG and SAPG was 0.879 , and the best cut-off value was $1.17 \mu \mathrm{g} / \mathrm{ml}$; AUC value of serum sRAGE in diagnosing NG and SAPG was 0.844 , and the best cut-off value was $372.00 \mathrm{pg} / \mathrm{ml}$; AUC value of serum sICAM-1 combined with sRAGE in diagnosing NG and SAPG was 0.939 , and the best cut-off value was 0.55 ; AUC value of serum sICAM-1 in diagnosing MAPG and SAPG was 0.783 , and the best cut-off value was $1.70 \mu \mathrm{g} / \mathrm{ml}$; AUC value of serum sRAGE in diagnosing MAPG and SAPG was 0.790 , and the best cut-off value was $494.70 \mathrm{pg} / \mathrm{ml}$; AUC value of serum sICAM-1 combined with sRAGE in diagnosing MAPG and SAPG was 0.856 , and the best cut-off value was 0.57 (Fig. 2, Table II).

Changes of intestinal mucosal barrier function before and after treatment. Before treatment, the concentrations of D-lactic acid, DAO and endotoxin in the SAPG were dramatically higher than those in the MAPG. After treatment, the concentrations in the SAPG were obviously lower than those before treatment, but still higher than those in the MAPG. The differences were statistically obvious $(\mathrm{P}<0.05)$ (Fig. 3).

Changes of T-lymphocyte subsets before and after treatment. Prior to treatment, $\mathrm{CD}^{+}, \mathrm{CD}^{+}, \mathrm{CD}^{+} / \mathrm{CD}^{+}$in the $\mathrm{SAPG}$ were remarkably lower than those in the MAPG. After 
Table II. ROC parameters of each group.

\begin{tabular}{llcccccc}
\hline Group & \multicolumn{1}{c}{ Indicators } & AUC & 95\% CI & Standard error & Cut-off value & Sensitivity (\%) & Specificity (\%) \\
\hline NG and MAPG & sICAM-1 & 0.799 & $0.714-0.885$ & 0.044 & $1.12 \mu \mathrm{g} / \mathrm{ml}$ & 63.79 & 93.33 \\
& sRAGE & 0.786 & $0.702-0.871$ & 0.043 & $393.10 \mathrm{pg} / \mathrm{ml}$ & 60.34 & 91.67 \\
& sICAM-1+sRAGE & 0.857 & $0.787-0.927$ & 0.036 & 0.61 & 68.97 & 96.67 \\
\multirow{2}{*}{ NG and SAPG } & sICAM-1 & 0.879 & $0.815-0.944$ & 0.033 & $1.17 \mu \mathrm{g} / \mathrm{ml}$ & 82.50 & 95.00 \\
& sRAGE & 0.844 & $0.777-0.912$ & 0.035 & $372.00 \mathrm{pg} / \mathrm{ml}$ & 72.50 & 90.00 \\
& sICAM-1+sRAGE & 0.939 & $0.897-0.981$ & 0.021 & 0.55 & 87.50 & 96.67 \\
MAPG and SAPG & sICAM-1 & 0.783 & $0.706-0.861$ & 0.040 & $1.70 \mu \mathrm{g} / \mathrm{ml}$ & 68.75 & 77.59 \\
& sRAGE & 0.790 & $0.714-0.866$ & 0.039 & $494.70 \mathrm{pg} / \mathrm{ml}$ & 57.50 & 89.66 \\
& sICAM-1+sRAGE & 0.856 & $0.791-0.920$ & 0.033 & 0.57 & 82.50 & 81.03 \\
\hline
\end{tabular}
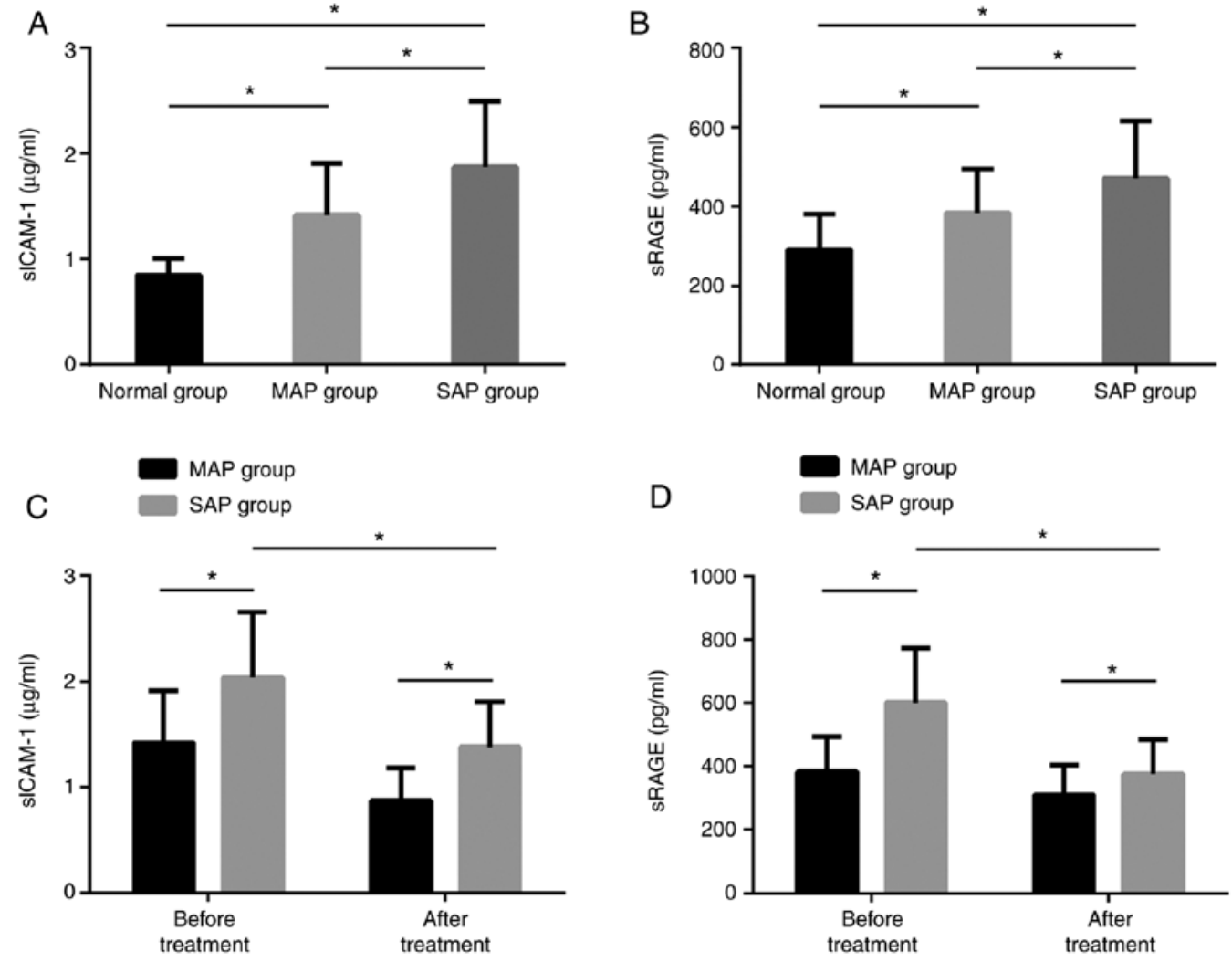

Figure 1. Expression of serum sICAM-1 and sRAGE. The expression of serum (A) sICAM-1 and (B) sRAGE in the SAPG is dramatically higher than that in the MAPG and the NG. (C) The expression of serum sICAM-1 in the SAPG after treatment is markedly lower than that before treatment, but still higher than that in the MAPG. (D) The expression of serum sRAGE in the SAPG after treatment is markedly lower than that before treatment, but still higher than that in the MAPG. ${ }^{*} \mathrm{P}<0.05$. sICAM-1, soluble intercellular adhesion molecule-1; sRAGE, soluble receptor for advanced glycation end products; SAPG, severe acute pancreatitis group; MAPG, mild acute pancreatitis group.
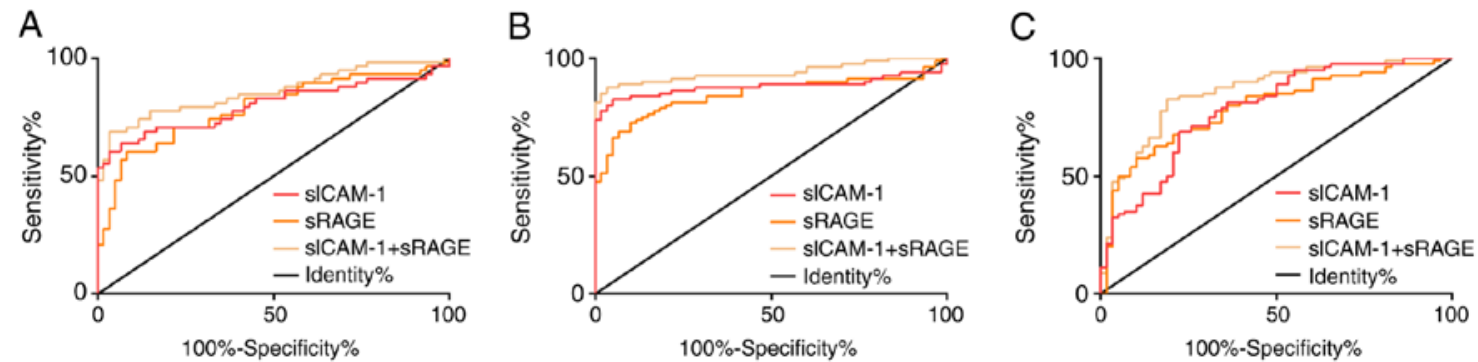

Figure 2. ROC curve of diagnostic value of serum sICAM-1 and sRAGE. Diagnostic value of serum sICAM-1 and sRAGE in the (A) NG and MAPG and the (B) NG and SAPG. (C) Diagnostic value of serum sICAM-1 and sRAGE in the MAPG and the SAPG. sICAM-1, soluble intercellular adhesion molecule-1; sRAGE, soluble receptor for advanced glycation end products; SAPG, severe acute pancreatitis group; MAPG, mild acute pancreatitis group; NG, normal group. 

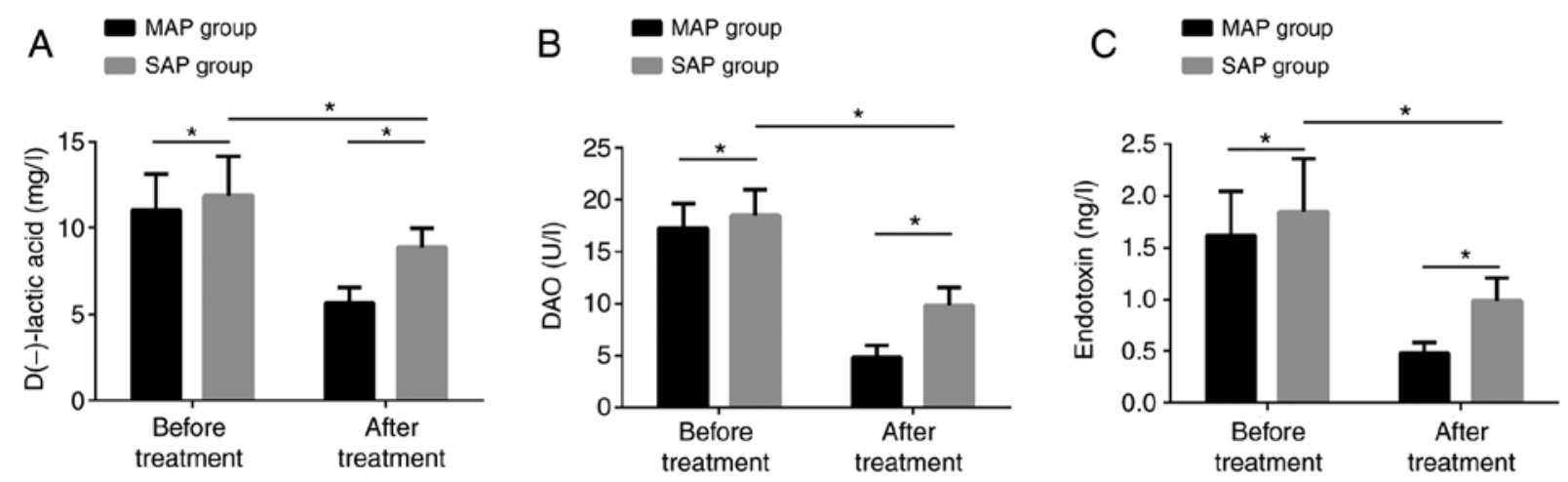

Figure 3. Changes of intestinal mucosal barrier function before and after treatment. (A) The expression of serum D-lactic acid in the SAPG after treatment is markedly lower than that before treatment, but still higher than that in the MAPG. (B) The expression of serum DAO in the SAPG after treatment is markedly lower than that before treatment, but still higher than that in the MAPG. (C) The expression of serum endotoxin in the SAPG is dramatically lower than that before treatment, but still higher than that in the MAPG. ${ }^{*} \mathrm{P}<0.05$. SAPG, severe acute pancreatitis group; MAPG, mild acute pancreatitis group. DAO, diamine oxidase.
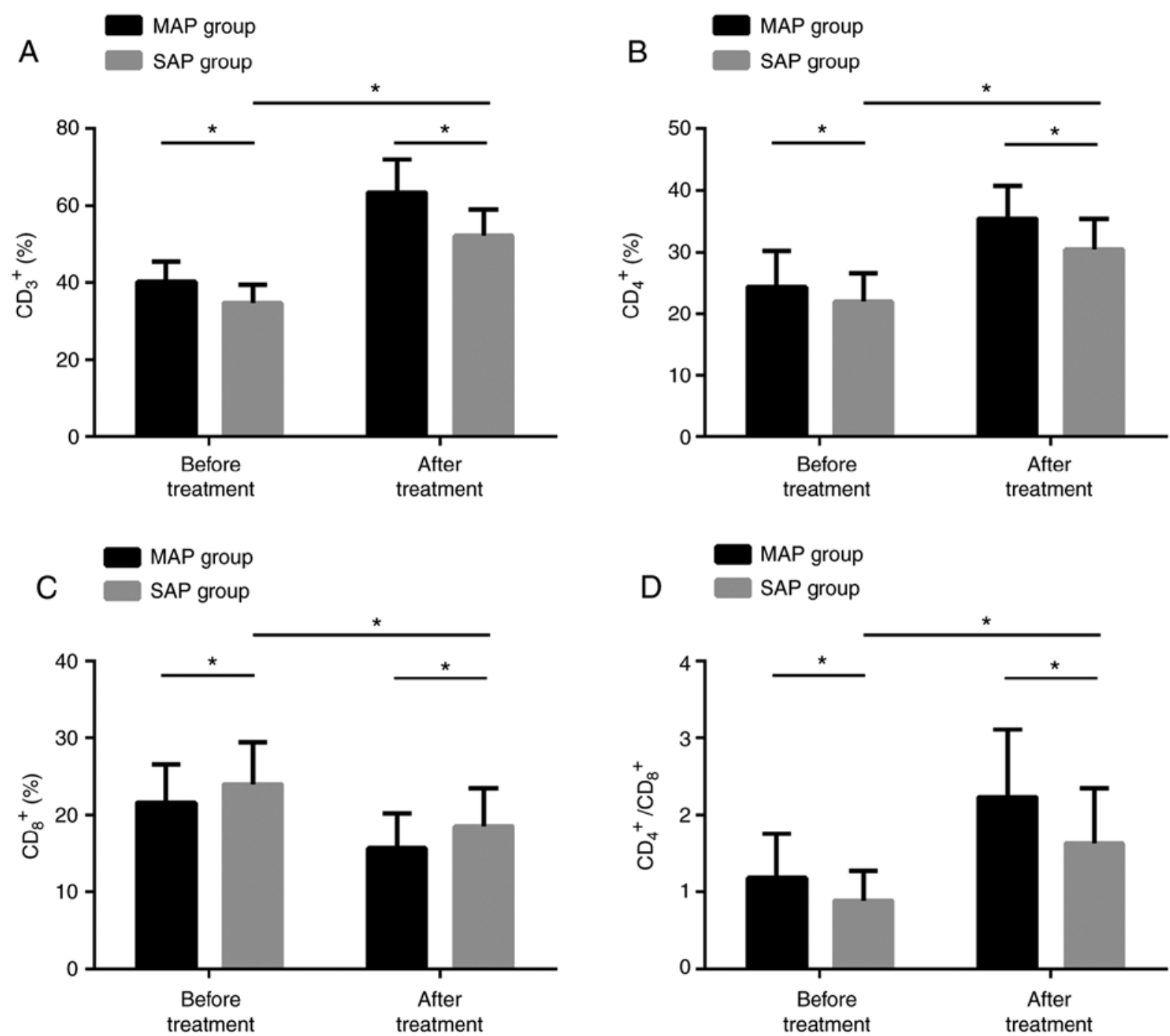

Figure 4. Changes of T-lymphocyte subsets before and after treatment. (A) The expression of $\mathrm{CD}^{+}$in the SAPG after treatment is markedly higher than that before treatment, but still lower than that in the MAPG. (B) The expression of CD4 ${ }^{+}$in the SAPG after treatment is dramatically higher than that before treatment, but still lower than that in the MAPG. (C) The expression of $\mathrm{CD}^{+}$in the SAPG after treatment is dramatically lower than that before treatment, but still higher than that in the MAPG. (D) The expression of $\mathrm{CD}^{+} / \mathrm{CD}^{+}$in the SAPG after treatment is markedly higher than that before treatment, but still lower than that in the MAPG. "P<0.05. SAPG, severe acute pancreatitis group; MAPG, mild acute pancreatitis group.

treatment, the three in the SAPG were dramatically higher than those before treatment, but still lower than those in the
MAPG, while $\mathrm{CD}^{+}$results were contrary to the other three. The difference was statistically marked $(\mathrm{P}<0.05)$ (Fig. 4). 
A

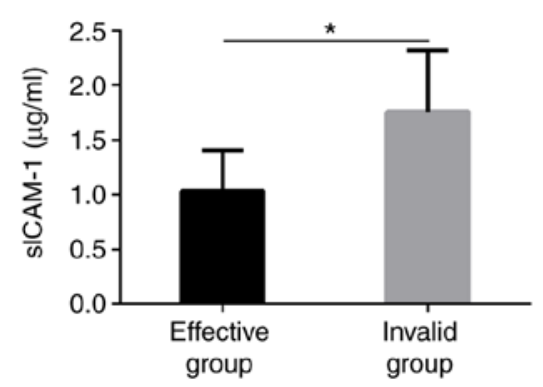

B

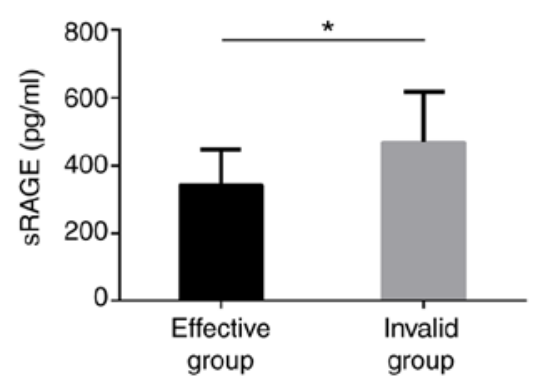

C

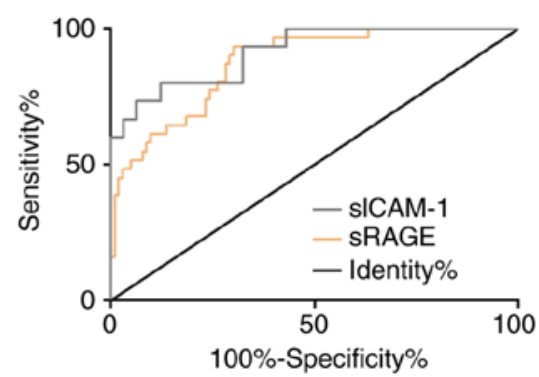

Figure 5. Predictive value of serum sICAM-1 and sRAGE for efficacy. (A) The expression of serum sICAM-1 in the IG is dramatically higher than that in the EG. (B) The expression of serum sRAGE in the IG is markedly higher than that in the EG. (C) Predictive value of serum sICAM-1 and sRAGE on efficacy, ${ }^{*} \mathrm{P}<0.05$. sICAM-1, soluble intercellular adhesion molecule-1; sRAGE, soluble receptor for advanced glycation end products; EG, effective group; IG, ineffective group.
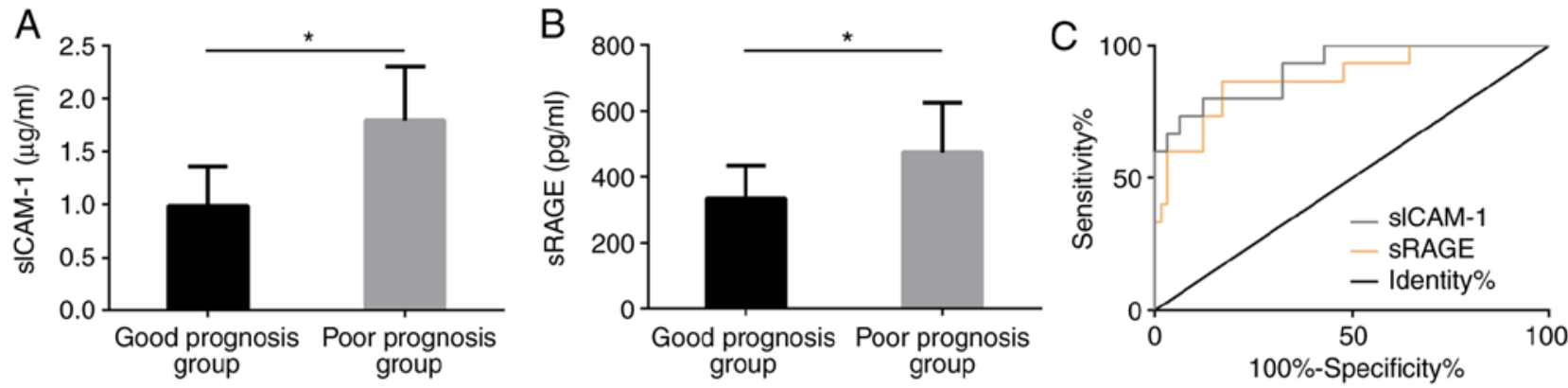

Figure 6. Predictive value of serum sICAM-1 and sRAGE for poor prognosis of SAP patients. (A) The expression of serum sICAM-1 in the PPG is markedly higher than that in the GPG. (B) The expression of serum sRAGE in the PPG is obviously higher than that in the GPG. (C) Predictive value of serum sICAM-1 and sRAGE for poor prognosis of SAP patients. "P<0.05. sICAM-1, soluble intercellular adhesion molecule-1; sRAGE, soluble receptor for advanced glycation end products; SAP, severe acute pancreatitis; PPG, poor prognosis group; GPG, good prognosis group.

Predictive value of serum SICAM-1 and sRAGE on efficacy. We divided AP patients into the EG and IG according to different efficacy of patients, including 103 cases with effective treatment (43 markedly effective and 60 effective cases) and 31 with ineffective treatment. The results showed that the sICAM-1 and sRAGE levels in serum of patients in EG were obviously lower than those in IG before treatment, and the difference was statistically marked $(\mathrm{P}<0.05)$. ROC analysis manifested that the predicted AUC of sICAM-1 for ineffective treatment was 0.920 , and the predicted AUC of sRAGE for ineffective treatment was 0.874 , all of which had good predictive value (Fig. 5).

Prognostic value of serum sICAM-1 and SRAGE in SAP patients. Based on whether SAP patients died within 30 days, 65 survivals were included in the GPG and the dead (15 individuals) were included in the PPG. After detecting the sICAM-1 and sRAGE levels in the serum of patients in both groups, we found that the levels in the serum of the GPG after treatment were markedly lower than those in the PPG, with statistically significant differences $(\mathrm{P}<0.05)$. After drawing ROC curve, we found that sICAM-1 had a good predictive value (0.914) for poor therapeutic prognosis in SAP patients and sRAGE also had a good predictive value (0.879) for their poor therapeutic prognosis (Fig. 6).

Univariate analysis of poor prognosis in SAP patients. After univariate analysis of patients in the GPG and the PPG, we found that there was no obvious difference in the average age, sex, etiology and other aspects $(\mathrm{P}>0.05)$. However, there were marked differences in multiple organ failure (MOF), acute respiratory distress syndrome (ARDS), acute renal failure (ARF), shock, liver function damage, sICAM-1, and sRAGE $(\mathrm{P}<0.05)($ Table III).

Multivariate analysis of poor prognosis in SAP patients. We analyzed MOF, ARDS, ARF, shock, liver function damage, sICAM-1, and SRAGE, and listed them as dependent variables for assignment. Whether there was a poor prognosis was taken as dependent variables, and logistic regression model was used for multivariate analysis. The results revealed that MOF, ARDS, ARF, shock, liver function damage, sICAM-1, and sRAGE were independent risk factors for poor prognosis (Tables IV and V).

\section{Discussion}

$\mathrm{AP}$ is an acute abdominal disease that can affect the function of multiple organs from local pancreatic damage. It is caused by pancreatic duct blockage, alcoholism, cationic trypsinogen gene mutation and other factors $(24,25)$. The minimal organ dysfunction accompanying MAP causes frequent attacks of AP, which may eventually progress to SAP or even pancreatic cancer (26). SAP is a severe acute inflammatory reaction of AP. The onset symptom is severe acute abdominal pain, and the prognosis is often poor (27). The study aimed to ameliorate the poor prognosis of SAP. 
Table III. Univariate analysis of poor prognosis in SAP patients [n (\%), mean \pm SD].

\begin{tabular}{|c|c|c|c|c|}
\hline Factor & $\begin{array}{l}\text { Good prognosis group } \\
\qquad(\mathrm{GPG})(\mathrm{n}=65)\end{array}$ & $\begin{array}{l}\text { Poor prognosis group } \\
\quad(\mathrm{PPG})(\mathrm{n}=15)\end{array}$ & $\chi^{2 / t}$ & P-value \\
\hline Average age (years) & & & 3.096 & 0.079 \\
\hline$<45$ & $38(58.46)$ & $5(33.33)$ & & \\
\hline$\geq 45$ & $27(41.54)$ & $10(66.67)$ & & \\
\hline Sex & & & 1.141 & 0.286 \\
\hline Male & $48(73.85)$ & $9(60.00)$ & & \\
\hline Female & $17(26.15)$ & $6(40.00)$ & & \\
\hline Etiology & & & 2.881 & 0.237 \\
\hline Biliary pancreatitis & $17(26.15)$ & 7 (46.67) & & \\
\hline Alcoholic pancreatitis & $12(18.46)$ & $3(20.00)$ & & \\
\hline Rests & $36(55.39)$ & $5(33.33)$ & & \\
\hline MOF & & & 13.396 & $<0.001$ \\
\hline No & $10(15.38)$ & $9(60.00)$ & & \\
\hline Yes & $55(84.62)$ & $6(40.00)$ & & \\
\hline ARDS & & & 5.970 & 0.015 \\
\hline No & $59(90.77)$ & $10(66.67)$ & & \\
\hline Yes & $6(9.23)$ & $5(33.33)$ & & \\
\hline ARF & & & 19.704 & $<0.001$ \\
\hline No & $62(95.38)$ & $8(53.33)$ & & \\
\hline Yes & $3(4.62)$ & 7 (46.67) & & \\
\hline Shock & & & 4.867 & 0.027 \\
\hline No & $58(89.23)$ & $10(66.67)$ & & \\
\hline Yes & 7 (10.77) & $5(33.33)$ & & \\
\hline Liver function damage & & & 12.062 & $<0.001$ \\
\hline No & $54(83.08)$ & $6(40.00)$ & & \\
\hline Yes & $11(16.92)$ & $9(60.00)$ & & \\
\hline sICAM-1 $(\mu \mathrm{g} / \mathrm{ml})$ & $0.99 \pm 0.37$ & $1.80 \pm 0.51$ & 7.091 & $<0.001$ \\
\hline sRAGE (pg/ml) & $334.84 \pm 100.98$ & $475.16 \pm 150.39$ & 4.394 & $<0.001$ \\
\hline
\end{tabular}

Table IV. Multivariate logistic regression analysis assignment.

\begin{tabular}{|c|c|c|}
\hline Factor & Variable & Assignment \\
\hline MOF & $\mathrm{X} 1$ & $\mathrm{No}=0, \mathrm{yes}=1$ \\
\hline ARDS & $\mathrm{X} 2$ & $\mathrm{No}=0$, yes $=1$ \\
\hline $\mathrm{ARF}$ & $\mathrm{X} 3$ & $\mathrm{No}=0, \mathrm{yes}=1$ \\
\hline Shock & $\mathrm{X} 4$ & $\mathrm{No}=0, \mathrm{yes}=1$ \\
\hline Liver function damage & X5 & $\mathrm{No}=0$, yes $=1$ \\
\hline sICAM-1 $(\mu \mathrm{g} / \mathrm{ml})$ & X6 & $\begin{array}{l}\text { The data belong to } \\
\text { continuous variables and } \\
\text { are analyzed with original } \\
\text { data. }\end{array}$ \\
\hline sRAGE (pg/ml) & $\mathrm{X} 7$ & $\begin{array}{l}\text { The data belong to } \\
\text { continuous variables and } \\
\text { are analyzed with original } \\
\text { data. }\end{array}$ \\
\hline
\end{tabular}

AP patients were treated by Glu combined with UTI. We collected the serum of patients after admission (before treatment) to evaluate the predictive value of sICAM-1 and SRAGE on efficacy, which had important guiding value for the matching degree and adaptability of patients before treatment. In addition, we collected the serum levels of sICAM-1 and sRAGE 7 days after treatment to analyze their predictive value for the prognosis of SAP patients under this treatment, which was of great significance to evaluate their potential as prognostic indicators for those under the treatment of Glu combined with UTI. Glu is a crucial free amino acid for maintaining intestinal mucosal barrier function and regulating immune response in human body. Based on SAP's large loss of UTI in vivo (28), we used Glu to supplement exogenous nutrition for patients. It was reported that UTI could repair SAP tissue damage and maintain immune homeostasis by regulating regulatory T cells (29). However, for AP patients, prediction of the severity of the disease and the efficacy of drug therapy still had timeliness and heterogeneity. It was necessary to detect other indicators to predict the condition, efficacy and prognosis of patients, so as to timely change the treatment plan and improve their prognosis. ICAM-1 is a cell surface protein that can participate in cell adhesion, inflammation, immune response and biological processes related to cancer. sICAM-1 is a soluble form of ICAM-1 and plays 
Table V. Multivariate analysis of poor prognosis in patients with ASP.

\begin{tabular}{lcccccc}
\hline Factor & $\beta$ & SE & Wald & P-value & OR & 95\% CI \\
\hline MOF & 0.169 & 0.077 & 4.997 & 0.023 & 1.962 & $1.087-1.347$ \\
ARDS & 0.621 & 0.252 & 6.835 & 0.016 & 1.832 & $1.103-2.874$ \\
ARF & 1.161 & 0.507 & 4.768 & 0.019 & 2.013 & $1.348-5.371$ \\
Shock & 0.338 & 0.108 & 9.935 & 0.032 & 1.399 & $1.137-1.736$ \\
Liver function damage & 0.020 & 0.066 & 3.692 & 0.020 & 1.389 & $1.021-1.710$ \\
sICAM-1 $(\mu \mathrm{g} / \mathrm{ml})$ & 1.247 & 0.507 & 4.768 & 0.001 & 3.201 & $1.235-8.672$ \\
sRAGE $(\mathrm{pg} / \mathrm{ml})$ & 0.756 & 0.298 & 6.584 & 0.012 & 2.217 & $1.231-3.816$ \\
\hline
\end{tabular}

MOF, multiple organ failure; ARDS, acute respiratory distress syndrome; ARF, acute renal failure; sICAM-1, soluble intercellular adhesion molecule-1; sRAGE, soluble receptor for advanced glycation end products.

an immunomodulatory role due to its binding with antigen 1 molecule tied to lymphocyte function $(30,31)$.

RAGE is a member of the pattern recognition receptor family, which can activate the inflammation regulation pathway by recognizing its ligand, and mediate cell migration, adhesion and production of pro-inflammatory molecules. As its soluble receptor, sRAGE's high expression is relevant to ligand accumulation at the injured site (32). Zhao et al (20) confirmed that the sRAGE expression in SAP patients was obviously higher than that of moderate MAP group (MSAPG), MAPG and healthy control group (HCG). AUC of sRAGE for predicting AP severity was 0.8304 , and the sensitivity and specificity were 91 and $81 \%$, respectively, suggesting that sRAGE had potential as an early diagnostic marker.

This research revealed that the serum sICAM-1 and sRAGE expression in the SAPG, MAPG and NG decreased markedly in turn. After treatment, the expression in the SAPG decreased compared with that before treatment, but was still higher than that in the MAPG, indicating that the two had potential value for early identification of AP disease. AUC values of serum sICAM-1 and sRAGE for combined diagnosis of NG and MAPG, NG and SAPG, MAPG and SAPG were 0.857, 0.939 and 0.856 , respectively, suggesting that serum sICAM-1 and sRAGE had higher predictive value for the combined diagnosis of AP patients and had the highest discriminating ability for NG and SAPG. After treatment, the injury indexes of intestinal mucosal barrier such as D-lactic acid, diamine oxidase (DAO) and endotoxin in the SAPG and the MAPG decreased obviously compared with those before treatment, but the indexes in the SAPG were higher than those in the MAPG, which indicated that Glu combined with UTI had different repair abilities for intestinal mucosal barrier in AP patients. Our immune function index test manifested that $\mathrm{CD}^{+}, \mathrm{CD}^{+}$, and $\mathrm{CD}^{+} / \mathrm{CD}^{+}$in the SAPG and the MAPG were remarkably higher after treatment than before treatment, but the index in the SAPG was lower than that in the MAPG, while $\mathrm{CD}^{+}$was opposite, indicating that Glu combined with UTI had improved immune function of AP patients to varying degrees. Research on efficacy prediction indicated that the sICAM-1 and sRAGE levels in the serum of patients in the EG were markedly lower than those in the IG before treatment. AUC of sICAM-1 and sRAGE for predicting ineffective treatment were 0.920 and 0.874 , respectively, which meant that the two had high predictive value for efficacy. Research on prognosis represented that the levels of serum sICAM-1 and sRAGE of patients in the GPG after treatment were dramatically lower than those in the PPG. AUC of sICAM-1 and sRAGE for predicting poor prognosis after treatment were 0.914 and 0.879 , respectively, which indicated that the two had high predictive value. Park et al (33) suggested that the AUC of APACHE II score for differentiating MAP from SAP and predicting the adverse prognosis of AP were 0.800 and 0.870 , respectively. We believe that serum sICAM-1 and sRAGE can play a great role in this aspect if they are used as biological complementary indicators of APACHE II. Finally, we performed univariate and multivariate analysis on poor prognosis, and found that MOF, ARDS, ARF, shock, liver function damage, sICAM-1, and sRAGE were independent risk factors.

In summary, although results of the present study confirmed that serum sICAM-1 and sRAGE had high predictive value for the early diagnosis, efficacy and prognosis of SAP patients treated with Glu and UTI; elevation of SICAM-1 and sRAGE were independent predictive factors for poor prognosis; but there is still some room for improvement. Firstly, we can increase the sample size of patients and improve the accuracy and universality of research. Secondly, we can increase sICAM-1 and sRAGE's mechanism in SAP and MAP in our basic experiments in the future.

\section{Acknowledgements}

Not applicable.

\section{Funding}

No funding was received.

\section{Availability of data and materials}

The datasets used and/or analyzed during the current study are available from the corresponding author on reasonable request.

\section{Authors' contributions}

LS and SB conceived and designed the study. LS and MZ were responsible for the collection and analysis of the experimental 
data. LS and SB interpreted the data and drafted the manuscript. LS wrote the manuscript. SB and MZ revised the manuscript critically for important intellectual content. All authors read and approved the final manuscript.

\section{Ethics approval and consent to participate}

The study was approved by the Ethics Committee of Yidu Central Hospital of Weifang, China. Patients who participated in this research signed the informed consent and had complete clinical data. Signed written informed consents were obtained from the patients and/or guardians.

\section{Patient consent for publication}

Not applicable.

\section{Competing interests}

The authors declare that they have no competing interests.

\section{References}

1. Van Dijk SM, Hallensleben NDL, van Santvoort HC, Fockens P, van Goor H, Bruno MJ and Besselink MG; Dutch Pancreatitis Study Group: Acute pancreatitis: Recent advances through randomised trials. Gut 66: 2024-2032, 2017.

2. Vege SS, DiMagno MJ, Forsmark CE, Martel M and Barkun AN: Initial medical treatment of acute pancreatitis: American gastroenterological association institute technical review. Gastroenterology 154: 1103-1139, 2018.

3. Mole DJ, Webster SP, Uings I, Zheng X, Binnie M, Wilson K, Hutchinson JP, Mirguet O, Walker A, Beaufils B, et al: Kynurenine-3-monooxygenase inhibition prevents multiple organ failure in rodent models of acute pancreatitis. Nat Med 22: 202-209, 2016

4. Maheshwari R and Subramanian RM: Severe acute pancreatitis and necrotizing pancreatitis. Crit Care Clin 32: 279-290, 2016.

5. Nesvaderani M, Eslick GD and Cox MR: Acute pancreatitis: Update on management. Med J Aust 202: 420-423, 2015.

6. Shah AP, Mourad MM and Bramhall SR: Acute pancreatitis: Current perspectives on diagnosis and management. J Inflamm Res 11: 77-85, 2018

7. Shamoon M, Deng Y, Chen YQ, Bhatia M and Sun J: Therapeutic implications of innate immune system in acute pancreatitis. Expert Opin Ther Targets 20: 73-87, 2016.

8. Wang B, Wu G, Zhou Z, Dai Z, Sun Y, Ji Y, Li W, Wang W, Liu C, Han F and Wu Z: Glutamine and intestinal barrier function. Amino Acids 47: 2143-2154, 2015.

9. Cruzat V, Macedo Rogero M, Noel Keane K, Curi R and Newsholme P: Glutamine: Metabolism and immune function, supplementation and clinical translation. Nutrients 10: 1564, 2018.

10. Alhan E, Usta A, Türkyılmaz S, Kural BV and Erçin C: Effects of glutamine alone on the acute necrotizing pancreatitis in rats. J Surg Res 193: 161-167, 2015.

11. Pan LL, Li J, Shamoon M, Bhatia M and Sun J: Recent advances on nutrition in treatment of acute pancreatitis. Front Immunol 8: $762,2017$.

12. Yong L, Lu QP, Liu SH and Fan H: Efficacy of glutamine-enriched nutrition support for patients with severe acute pancreatitis: A meta-Analysis. JPEN J Parenter Enteral Nutr 40: 83-94, 2016.

13. Liu B, Huang W, Xiao X, Xu Y, Ma S and Xia Z: Neuroprotective effect of ulinastatin on spinal cord ischemia-reperfusion injury in rabbits. Oxid Med Cell Longev 2015: 624819, 2015.

14. Xu R, Jiang S, Zhou H and Jin W: Clinical efficacy of ulinastatin combined with somatostatin for treatment of severe acute pancreatitis and effects on immune function. Int J Clin Exp Med 12: 11333-11341, 2019.
15. Li C, Ma D, Chen M, Zhang L, Zhang L, Zhang J, Qu X and Wang C: Ulinastatin attenuates LPS-induced human endothelial cells oxidative damage through suppressing JNK/c-Jun signaling pathway. Biochem Biophys Res Commun 474: 572-578, 2016.

16. Wei F, Liu SY, Luo L, Gu N, Zeng Y, Chen X, Xu S and Zhang D: Anti-inflammatory mechanism of ulinastatin: Inhibiting the hyperpermeability of vascular endothelial cells induced by TNF- $\alpha$ via the RhoA/ROCK signal pathway. Int Immunopharmacol 46: 220-227, 2017.

17. Schellerer VS, Langheinrich MC, Zver V, Grützmann R, Stürzl M, Gefeller O, Naschberger E and Merkel S: Soluble intercellular adhesion molecule-1 is a prognostic marker in colorectal carcinoma. Int J Colorectal Dis 34: 309-317, 2019.

18. Staubli SM, Oertli D and Nebiker CA: Laboratory markers predicting severity of acute pancreatitis. Crit Rev Clin Lab Sci 52: 273-283, 2015

19. Bopp C, Hofer S, Weitz J, Bierhaus A, Nawroth PP, Martin E, Büchler MW and Weigand MA: sRAGE is elevated in septic patients and associated with patients outcome. J Surg Res 147: 79-83, 2008.

20. Zhao B, Chen Y, Sun WW, Chen WW, Ma L, Yang ZT, Huang J, Chen EZ, Fei J and Mao EQ: Effect of S100A12 and soluble receptor for advanced glycation end products on the occurrence of severe acute pancreatitis. J Dig Dis 17: 475-482, 2016.

21. Greenberg JA, Hsu J, Bawazeer M, Marshall J, Friedrich JO, Nathens A, Coburn N, May GR, Pearsall E and McLeod RS: Clinical practice guideline: Management of acute pancreatitis. Can J Surg 59: 128-140, 2016.

22. Akavipat $P$, Thinkhamrop J, Thinkhamrop B and Sriraj W: Acute physiology and chronic health evaluation (APACHE) II score-the clinical predictor in neurosurgical intensive care unit. Acta Clin Croat 58: 50-56, 2019.

23. Hornbeck PV: Enzyme linked immunosorbent assays. Curr Protoc Immunol 110: 2.1.1-2.1.23, 2015.

24. Yang ZW, Meng XX and Xu P: Central role of neutrophil in the pathogenesis of severe acute pancreatitis. J Cell Mol Med 19: 2513-2520, 2015.

25. Manohar M, Verma AK, Venkateshaiah SU, Sanders NL and Mishra A: Pathogenic mechanisms of pancreatitis. World J Gastrointest Pharmacol Ther 8: 10-25, 2017.

26. Saluja A and Maitra A: Pancreatitis and pancreatic cancer. Gastroenterology 156: 1937-1940, 2019.

27. Shen $X$ and Li WQ: High-mobility group box 1 protein and its role in severe acute pancreatitis. World J Gastroenterol 21: 1424-1435, 2015.

28. Yang C, Wen J, Xia M and Wang SR: Effect of glutamine nutrition support on the intestinal mucosal barrier function and inflammatory response in patients with severe acute pancreatitis. J Hainan Med Univ 23: 17-21, 2017.

29. Pan Y, Fang H, Lu F, Pan M, Chen F, Xiong P, Yao Y and Huang H: Ulinastatin ameliorates tissue damage of severe acute pancreatitis through modulating regulatory T cells. J Inflamm (Lond) 14: 7, 2017.

30. Kuessel L, Wenzl R, Proestling K, Balendran S, Pateisky P, Yotova I, Yerlikaya G, Streubel B and Husslein H: Soluble VCAM-1/soluble ICAM-1 ratio is a promising biomarker for diagnosing endometriosis. Hum Reprod 32: 770-779, 2017.

31. Budnik A, Grewe M, Gyufko K and Krutmann J: Analysis of the production of soluble ICAM-1 molecules by human cells. Exp Hematol 24: 352-359, 1996.

32. Scavello F, Zeni F, Tedesco CC, Mensà E, Veglia F, Procopio AD, Bonfigli AR, Olivieri F and Raucci A: Modulation of soluble receptor for advanced glycation end-products (RAGE) isoforms and their ligands in healthy aging. Aging (Albany NY) 11: 1648-1663, 2019

33. Park JY, Jeon TJ, Ha TH, Hwang JT, Sinn DH, Oh TH, Shin WC and Choi WC: Bedside index for severity in acute pancreatitis: Comparison with other scoring systems in predicting severity and organ failure. Hepatobiliary Pancreat Dis Int 12: 645-650, 2013.

This work is licensed under a Creative Commons Attribution-NonCommercial-NoDerivatives 4.0 International (CC BY-NC-ND 4.0) License. 